\title{
Avaliação morfológica de células endoteliais cultivadas
}

\author{
Morphology evaluation of cultivated endothelial cells
}

\author{
Carolina Nunes França ${ }^{1 *}$; Jônatas Bussador do Amaral ${ }^{2 *}$; Maria Cristina de Oliveira Izar ${ }^{3}$; \\ Francisco Antonio Helfenstein Fonseca ${ }^{3}$ \\ ${ }^{1}$ Doutora em Ciências - UNIFESP. São Paulo, SP - Brasil. \\ 2Doutor em Ciências - USP. São Paulo, SP - Brasil. \\ ${ }^{3}$ Professores Afiliados da Disciplina de Cardiologia - UNIFESP. São Paulo, SP - Brasil. \\ Endereços para correspondência \\ Jônatas Bussador do Amaral \\ Av. Prof. Lineu Prestes, 1524, ICB1, $3^{\circ}$ andar, sala 306. \\ 05508900 - Cidade Universitária. \\ São Paulo, SP - Brasil \\ amaraljb@gmail.com
}

\begin{abstract}
Resumo
Introdução: A origem de células endoteliais cultivadas tem sido alvo de investigações. Essas células podem ser originadas não só a partir de progenitoras endoteliais verdadeiras, mas também de monócitos, que igualmente são capazes de aumentar o processo de angiogênese. Além disso, estudos mostram que progenitoras endoteliais apresentam características que são próprias de monócitos. Objetivo: Neste estudo, objetivou-se avaliar morfologicamente células endoteliais cultivadas, que são chamadas de early células progenitoras endoteliais. Métodos: As células mononucleares do sangue periférico foram cultivadas por nove dias, e durante o cultivo foram realizadas imagens em microscópio invertido e em confocal. Resultados: Observou-se a presença de populações celulares que se apresentaram com um aspecto alongado e que estiveram sempre associadas em pequenos agregados (colônias). Conclusão: Ainda são necessários muitos estudos buscando a padronização de técnicas mais sensíveis para obtenção, identificação e quantificação de CPEs cultivadas.
\end{abstract}

Descritores: Células progenitoras; Endotélio; Técnicas de cultura celular.

\begin{abstract}
Introduction: The origin of cultivated endothelial cells has been target of investigations. These cells can be originated not only from true endothelial cells, but also from monocytes, that equally are able to increase the angiogenesis process. Furthermore, studies showed that endothelial progenitor cells have characteristics that are own of monocytes. Objectives: The aim in this work was to evaluate the morphology of cultivated endothelial cells, which are named "early" endothelial progenitor cells. Methods: The mononuclear cells of peripheral blood were cultivated for nine days, and during the cultive images were acquired by inverted and confocal microscopy. Results: We observed the presence of cellular populations with elongated shape that were associated in small aggregates (colonies). Conclusion: There is still a need for further studies focusing the standardization of more sensitive techniques for obtaining, identifying and quantifying cultivated EPCs.
\end{abstract}

Key words: Cell culture techniques; Endothelium; Progenitor Cells. 


\section{Introdução}

A medula óssea é a principal fonte de células progenitoras endoteliais (CPEs) em adultos. A mobilização prejudicada de CPEs na corrente sanguínea está relacionada a doenças cardiovasculares; e indivíduos com reduzido número de CPEs circulantes possuem maior risco para desenvolver doença arterial coronariana $(\mathrm{DAC})^{1-3}$. E o inadequado desenvolvimento colateral coronário em pacientes com DAC também está relacionado com um menor número de CPEs circulantes ${ }^{4}$.

Inicialmente, acreditava-se que a regeneração do endotélio danificado e a formação de novos vasos ocorressem exclusivamente devido à proliferação de células endoteliais maduras. Entretanto, a capacidade dessas células em substituir o endotélio danificado é limitada 5 . Em 1997, Asahara et al. ${ }^{6}$ isolaram células mononucleares do sangue periférico, e verificaram que essas células migraram da medula óssea para áreas de isquemia, podendo se diferenciar para um fenótipo endotelial.

A vasculogênese é um processo em que novos vasos são formados por CPEs ou angioblastos que migram, que se diferenciam e que se proliferam em resposta a vários estímulos. A angiogênese ocorre quando novos vasos são formados pela migração e diferenciação de células endoteliais maduras já existentes. Atualmente, sabe-se que vasculogênese e angiogênese têm um papel sinérgico na revascularização pós-natal, ${ }^{7,8}$.

O estudo de CPEs é dificultado pelos seguintes fatores: (1) constitui uma população extremamente rara no sangue periférico, representando entre $0,01 \%$ e $0,0001 \%$ das células mononucleares ${ }^{9}$; (2) não possui uma proteína de superfície que não seja expressa em outras células, sendo necessária a identificação de pelo menos duas proteínas de superfície para que essa célula possa ser estudada ${ }^{10}$.

CPEs expressam diferentes marcadores de superfície, dependendo do seu estado de diferenciação in vitro. As células progenitoras endoteliais imaturas expressam marcadores de células hematopoiéticas, tais como CD133, CD34, KDR (receptor 2 do fator de crescimento endotelial vascular - VEGFR 24, ${ }^{4,11}$ e marcadores de monócitos/macrófagos, como o CD11 e o CD14 ${ }^{8}$. Quando maduras, o CD133 deixa de ser expresso e passa a expressar-se o CD31, além de outros marcadores típicos de células endoteliais, como o vWF ${ }^{4,12}$, VE-caderina ${ }^{4,11,13}$, Tie-2, CD146 e E-selectina ${ }^{11}$.

Alguns estudos sugerem que a expansão ex vivo de CPEs pode aumentar o pool dessas células, e após a proliferação in vitro elas podem ser injetadas intravenosamente ou diretamente no músculo cardíaco participando, assim, da regeneração vascular e do remodelamento cardíaco ${ }^{11}$. Há dois tipos de CPEs descritas na literatura de acordo com a capacidade proliferativa e origem, são elas: early e late. As early CPEs surgem por volta de quatro dias de cultivo, têm a capacidade de formar colônias, tornam-se alongadas após uma semana, têm baixo potencial proliferativo e podem se originar a partir de monócitos; por isso, não seriam progenitoras endoteliais verdadeiras. As late CPEs aparecem após três semanas de cultivo, têm alta capacidade proliferativa, são alongadas e possivelmente são originadas a partir de progenitoras endoteliais verdadeiras; por esse motivo, são também chamadas de true CPEs ${ }^{14}$.

Outros trabalhos classificam as CPEs de acordo com o tamanho e morfologia. Nos primeiros dias de cultivo, predominam células arredondadas e, após seis semanas, ocorre aumento de células aderidas que se tornam alongadas. Além disso, depois de três dias de cultivo as células progenitoras endoteliais podem ser divididas em duas subpopulações - pequenas e grandes CPEs - que persistem até duas semanas de cultivo. Após três semanas de cultivo, apenas uma população pode ser visualizada, compondo uma cultura de células endoteliais maduras ${ }^{15}$.

Com base nesses dados, o objetivo neste trabalho foi avaliar morfologicamente células endoteliais cultivadas durante nove dias, chamadas de early CPEs de acordo com a literatura. 


\section{Métodos}

\section{Coleta de dados clínicos}

Foram realizadas visitas clínicas para coleta dos dados, tais como fatores de risco, exame clínico, eletrocardiograma e coletas de amostras de sangue.

O trabalho foi encaminhado ao Comitê de Ética em Pesquisa da Universidade Federal de São Paulo e os pacientes foram incluídos após assinatura do Termo de Consentimento Livre e Esclarecido (TCLE), de acordo com as orientações para pesquisa com seres humanos constantes na Resolução 196/96 do Conselho Nacional de Saúde, obedecendo-se os critérios de inclusão/exclusão específicos do trabalho.

As amostras de sangue colhidas dos participantes da pesquisa foram obtidas após jejum de 12 a 14 horas. As coletas foram realizadas no Setor de Lípides, Aterosclerose e Biologia Vascular da Disciplina de Cardiologia do Departamento de Medicina da Escola Paulista de Medicina da Universidade Federal de São Paulo.

\section{Cultivo celular e microscopia}

O sangue periférico dos pacientes foi colhido em tubo com EDTA para evitar coagulação, sendo acrescido Ficoll-Hypaque (GE Healthcare) para obtenção de células mononucleares, que foram cultivadas por nove dias em meio propício ao desenvolvimento de células endoteliais (Meio 199, LGC Biotecnologia). Durante o cultivo, foram obtidas imagens das culturas em microscópio invertido (Coleman NIB 100, Coleman Equipamentos para Laboratório Comércio e Importação, Ltda.). Após a lavagem dessas células em solução de PBSA (repetida três vezes em todos os procedimentos), elas foram fixadas com formaldeído 3,7\%, em PBSA, por 30 minutos. Novamente lavadas, as células foram expostas a uma solução permeabilizadora de Triton-x 100 0,5\% por igual período. Para a detecção dos microfilamentos de actina, foi utilizada uma solução contendo faloidina acoplada a isoticianato de fluorceina (FITC), Sigma ${ }^{\circledR}$, na concentra- ção de 7,5 $\mu \mathrm{M}$ em PBSA. As células ficaram em contato com essas substâncias por um período de 40 minutos, sendo posteriormente lavadas com PBSA (três vezes). As marcações nucleares foram feitas por meio de um corante específico para ácidos nucleicos, o iodeto de propídeo, na concentração de $10 \mu \mathrm{g} / \mathrm{mL}$ (Sigma®). Devido ao interesse somente pelo DNA, as células ficaram em contato com uma solução de RNAase (10 $\mathrm{mg} / \mathrm{mL}$ ) por uma hora. Após isso, elas foram lavadas em PBSA, sendo, então, adicionado 8 $\mu \mathrm{l}$ de solução protetora de fluorescência, e $2 \mu \mathrm{l}$, de solução de iodeto de propídeo, em seguida, o conjunto foi colocado sob uma lâmina de vidro. As lamínulas de vidro foram vedadas com esmalte de unha, acondicionadas em ambiente escuro e mantidas a $-20{ }^{\circ} \mathrm{C}$. As células foram analisadas ao microscópio confocal de varredura a laser (Zeiss LSM 510). As imagens fluorescentes foram adquiridas utilizando-se lasers de Argônio (458, 488, e 514 nm), Hélio-Neônio1 (543 nm) e Hélio-Neônio2 (633 nm). As fatias ópticas foram obtidas em intervalos adequados no eixo $\mathrm{Z}$, entre 0,5 e $1 \mu \mathrm{m}$. Diferentes módulos do software LSM 510 3D (Carl Zeiss ${ }^{\circledR}$ ) foram utilizados na análise confocal, os quais incluem projeções das fatias e animações. Algumas reconstruções e animações foram feitas no software IMARIS 7.1 (Bitplane $\left.{ }^{\circledR}\right)^{16}$.

\section{Resultodos}

Ao longo do tempo de cultura, observou-se uma gradativa adesão das células em suspensão (Figura $1 \mathrm{~A}$ ) a qual veio acompanhada por mudanças na morfologia celular. Essas alterações culminaram na presença de populações celulares que se mostraram com um aspecto alongado (Figura 1 B e C). Analisadas com maior detalhe ao microscópio confocal de varredura a laser, foi possível observar que essas células mais alongadas estiveram sempre associadas a pequenos agregados (colônias) e, na maioria dos casos, essas células mais diferenciadas encontraram-se margeando tal agrupamento (Figura 1 D). As re- 
construções dos cortes ópticos possibilitou visualizar pontuações fortemente marcadas pela faloidina (Figura $1 \mathrm{E}$ e F), estando essas estruturas voltadas para a superfície da lamínula. A organização dessas pontuações é muito semelhante ao encontrado para contatos focais (Figura $1 \mathrm{~F}$ ). Algumas células também apresentaram projeções de membrana, as quais apontam para processos migratórios (Figura G).

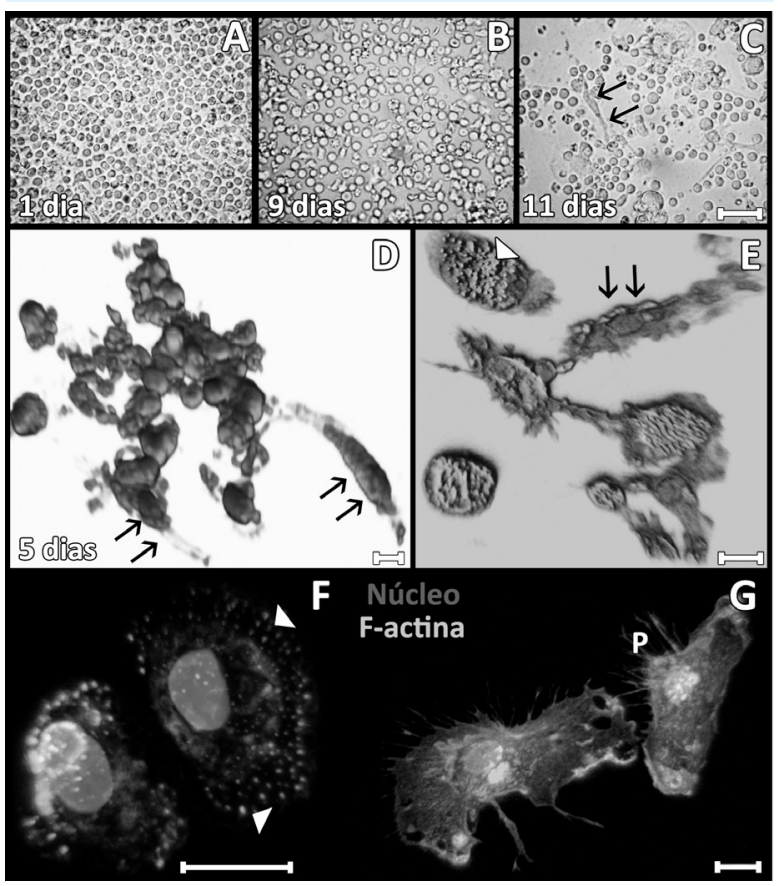

Figura l: Células endoteliais vistas ao microscópio de luz invertido com contraste de fase ao longo do tempo de cultura (A-C). As figuras D-G foram obtidas ao microscópio confocal de varredura a laser, sendo possível observar pontuações fortemente marcadas pela faloidina (cabeça de seta) (em F) bem como projeções de membrana (P) (em G). A seta dupla indica células diferenciadas com morfologia

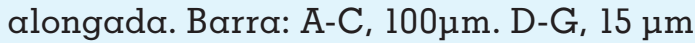

\section{Discussão e conclusão}

De acordo com a literatura, as células progenitoras endoteliais circulam no sangue periférico e são recrutadas a partir da medula óssea após alguns estímulos, tais como estatinas, atividade física e citocinas ${ }^{17,18}$.
Há muitas controvérsias com relação à origem de células endoteliais cultivadas. Em estudos mostram-se que monócitos são capazes de aumentar o processo de angiogênese e que progenitoras endoteliais apresentam características que são próprias de monócitos ${ }^{13}$.

Tanto as células endoteliais obtidas de progenitoras positivas para CD34, KDR e CD133 ${ }^{19}$ como as originadas de populações CD14+, têm potencial angiogênico e expressam os marcadores de células endoteliais maduras fator von Willebrand (vWF), VE-caderina,CD146, e CD316. Além disso, tais células são capazes de formar colônias e têm maior expressão de eNOS após turbilhonamento ${ }^{20}$.

Nos últimos anos, estudos têm avaliado o efeito da terapia celular com o intuito de promover a vascularização em tecidos sofrendo regeneração. Tem sido sugerido que o tratamento de pacientes com doença cardiovascular com progenitoras endoteliais cultivadas, obtidas a partir de células mononucleares do sangue periférico, possa trazer benefícios terapêuticos, embora se estima que seriam necessárias elevadas quantidades de sangue para que se conseguisse um número mínimo necessário que gerasse resultados favoráveis ${ }^{13}$. Ainda são necessários muitos estudos buscando a padronização de técnicas mais sensíveis para a obtenção, identificação e cultivo de $\mathrm{CPE}$, pois são aspectos, até o momento, pouco explorados na literatura mundial.

\section{Agrodecimentos}

Os autores agradecem à professora doutora Gláucia Maria Machado-Santelli do Departamento de Biologia Celular e do Desenvolvimento pela utilização do microscópio confocal.

\section{Nota}

* Os dois primeiros autores contribuíram de igual maneira na elaboração deste estudo. 


\section{Referências}

1. Thum T, Fraccarollo D, Galuppo P, Tsikas D, Frantz $S$, Ertl G, et al. Bone marrow molecular alterations after myocardial infarction: impact on endothelial progenitor cells. Card Res. 2006;70:50-60.

2. Werner N, Kosiol S, Schiegl T, Ahlers P, Walenta K, Link A, et al. Circulating endothelial progenitor cells and cardiovascular outcomes. N Engl J Med. 2005;353:999-1007.

3. Schmidt-Lucke C, Rössig L, Fichtlscherer S, Vasa M, Britten M, Kämper U, et al. Reduced number of circulating endothelial progenitor cells predicts future cardiovascular events proof of concept for the clinical importance of endogenous vascular repair. Circulation. 2005;111:2981-7.

4. Lambiase PD, Edwards RJ, Anthopoulos P, Rahman S, Meng YG, Bucknall CA, et al. Circulating humoral factors and endothelial progenitor cells in patients with differing coronary collateral support. Circulation. 2004;109:2986-92.

5. Hristov M, Fach C, Becker C, Heussen N, Liehn EA, Blindt $R$, et al. Reduced numbers of circulating endothelial progenitor cells in patients with coronary artery disease associated with long-term statin treatment. Atherosclerosis. 2007;192:413-20.

6. Asahara T, Murohara T, Sullivan A, Silver M, van der Zee R, Li T. et al. Isolation of putative progenitor endothelial cells for angiogenesis. Science. 1997;275:964-7.

7. Carmeliet P, Moons L, Stassen JM, De Mol M, Bouche A, Van den Oord JJ, et al. Vascular wound healing and neointima formation induced by perivascular electric injury in mice. Am J Pathol. 1997;150:761-76.

8. Liew A, Barry F, O'Brien T. Endothelial progenitor cells: diagnostic and therapeutic considerations. BioEssays. 2006;28:261-70.

9. Khan SS, Solomon MA, McCoy JP, Jr. Detection of circulating endothelial cells and endothelial progenitor cells by flow cytometry. Cytometry B Clin Cytom. 2005;64(1):1-8.
10. Hristov M, Erl W, Weber PC. Endothelial Progenitor Cells: Mobilization, Differentiation and Homing. Arterioscler Thromb Vasc Biol. 2003;23:1185-9.

11. Rafii S, Lyden D. Therapeutic stem and progenitor cell transplantation for organ vascularization and regeneration. Nature Med. 2003;9(6):702-12.

12. Hristov M, Weber C. Endothelial progenitor cells: characterization, pathophysiology, and possible clinical relevance. J Cell Mol Med. 2004;8(4):498-508.

13. Rehman J, Li J, Parvathaneni L, Karlsson G, Panchal VR, Temm CJ, et al. Exercise acutely increases circulating endothelial progenitor cells and monocyte-/macrophage-derived angiogenic cells. J Am Coll Cardiol. 2004;43:2314-8.

14. Hur J, Yoon CH, Kim HS, Choi JH, Kang HJ, Hwang KK, et al. Characterization of two types of endothelial progenitor cells and their different contributions to neovasculogenesis. Arterioscler Thromb Vasc Biol. 2004;24:288-93.

15. Werner N, Nickenig G. Endothelial progenitor cells in health and atherosclerotic disease. Ann Med. 2007;39(2):82-90.

16. Amaral JB do, Urabayashi M S, Machado-Santelli G $\mathrm{M}$. Cell death and lumen formation in spheroids of MCF-7 cells. Cell Biol Int. 2010;34(3):267-74.

17. Yamamoto H, Kato H, Uruma M, Nitta M, Takamoto S. Identification of two distinct populations of endothelial progenitor cells differing in size and antigen expression from human umbilical cord blood. Ann Hematol. 2008;87:87-95.

18. Fonseca FAH, França CN, Povoa RMS, Izar MCO. Estatinas y accidente cerebrovascular: posibles mecanismos de acción de la protección neurovascular. Rev Neurol. 2010;51:551-60.

19. França CN; Fonseca FAH; Izar, MCO. Células endoteliais circulantes, progenitoras endoteliais e micropartículas. Rev Soc Cardiol Estado de São Paul. 2010;20:158-165.

20. Vasa M, Fichtlscherer S, Aicher A, Adler K, Urbich $C$, Martin $\mathrm{H}$, et al. Number and migratory activity of circulating endothelial progenitor cells inversely correlate with risk factors for coronary artery disease. Circ Res. 2001;89:E1-E7. 